\title{
Covid-19 and Auditing
}

\author{
Emmanuel John Kaka,"* \\ aAccounting Department, Federal University Gashua, youngkaka2002@yahoo.co.uk, Nigeria
}

\begin{abstract}
COVID-19 has affected the way and manner financial statements are prepared, and audit engagements, information gathering and reporting. The aim of the paper is to highlights some of the practical challenges auditors may face in auditing financial statements of an organization in the light of COVID-19 and areas to put more emphasis in their audit reports. Documentary research design was employed and secondary data sources were collected and used for this research. The paper found out that Professional associations, accounting and auditing bodies are monitoring issues and situations as they unfold that may affect the financial statements and audits reports due to the impact of COVID-19. Moreover, they are ready all the time to issue out additional guidelines as new development unfold, and continue to update professional accountants on issues patterning to the continuity of the organization business, workforce, economic impact and other resources to help their members to serve their clients better in this period of pandemic. The paper recommends that Auditors are expected to display enough professional skepticism and judgement and be focused on public interest and ethical responsibilities bestowed on them, and continue to apply the principles contain in auditing standards fully, as well as comply with the fundamental principles of professional competence, confidentiality, objectivity, independence, care and skills and behave professionally, as keys that will preserve and expand auditors trust in the face of the public.
\end{abstract}

Keywords: Auditors, Audit reports, Covid-19, Financial statements, Management, Organization. 


\section{Introduction}

The outbreak of COVID-19 (coronavirus) disease in 2019 from China to other part of the world, is having an unprecedented and widespread effects on the global financial markets and it may have accounting and auditing implication for businesses and ongoing economy of the world in different dimension, particularly the financial reporting for March 2020 which is presented for subsequent reporting periods (Chan \& Lee, 2020; Shires, 2020). Thus, organizations must have to look at their unique situations and exposure to risk and consider the effects of the outbreak on their audit reports. Some of the areas that will be affected in an organization are; reduction in sales, productivity or earnings, inability to raise finance, production interruptions, closure of factories and stores, delay in business planned expansions, supply chain disruptions increase volatility, un availability of personnel, reduced tourism, leisure, disruptions in nonessential travels and sports (Poole, 2020).

These has affected audit engagements, which has many and complex consequences that posit a great challenge to the auditors and those given the responsibility and power to govern (the management) (Arnold, 2020). Most especially, at this time that auditors and the preparers of financial statements are vividly and practically affected by the movement control orders, as everyone stays at home, with the expectation that management should gather data and information in a different manner from the normal and operate controls over the preparations and production of the information in a different way (Arnold, 2020). However, financial statements and audit reports disclosures, need to discover and disclose all the material effects of coronavirus (Poole, 2020).

The coronavirus pandemic crisis which has affected the economies of the world, is an indication that investors and stakeholders may desire and require high quality audit and financial information more than it was before (Gould \& Arnold, 2020), and these will increase the need for quality audit expectation from auditors. Hence, some other audit challenges that have not being faced by auditors in undertaken audit assignments have come up, from increased pressure to complete audit work to issues in getting audit evidence and very sensitive judgements in areas such as going concern. However, despite the challenges, auditors are required to evaluate them and undertake normal auditing functions (Suffied, 2020).
In order for the auditors to response to such challenges and meet the expectations of investors and stakeholders, auditors are required to be more agile and creative in carrying out their audit task in compliance with standards procedures. And need to be reminded that while auditing standards procedures outlined the performance requirement for obtaining reasonable audit evidence and assurance from the financial statements to be free from material misstatement, the auditing standard did not set specific requirements on how to obtain them at this critical moment that auditors are expected to rely on technology in performing audit procedures (Illuzzi et al., 2020).

Therefore, as digital advances keep affecting the way audit are carried out, covid-19 pandemic has fast tract the quest for the usage of technology in auditing, most especially in the aspect of the procedure for gathering audit evidence and reports. This crisis has created a systematic shock to normal clients' engagement in their business organization. Suffield (2020) opined that auditors will definitely require to re-evaluate the way and manner they carry out the usual audit work. From issues in getting audit evidence, to increase in pressure to conclude audit assignment, and very sensitive judgements in the aspect of going concern, while trying to use technology (Thompson, 2020).

At this moment of covid-19, most directors and external auditors have raised concern about how stakeholders and financial institutions may analyzed and interpret the audit reports of an organization. Since majority of the organizations have entered an agreement that may possibly not be fulfilled with an unqualified audit reports in the financial statement. This scenario is unique in nature, which indicates or means that auditors may not have options, rather than to qualify the audit reports (Shires, 2020). This issue prompted the writing of this paper to highlight some of the practical challenges auditors may face in auditing financial statements in the light of covid-19 and areas to emphasise their audit reports. Apart from introduction, section two deals with literature review on auditing issues and COVID-19, section three discusses the method used in data collection and section four conclude the study.

\section{Literature Review}

Auditing is an activity that involves examination or inspection of a procedures or quality system, in compliance with the standard requirements put in 
place. An audit can be undertaken for a specific section or function, or for a production step, or for a whole organization. Auditing can also have said to be an accounting practice that has to do with checking the correctness of financial records of an organization. It may involves investigating an organization or individuals, physical assets such as stocks, real estate, and equipment's. Therefore, auditor is required to review not only the records and financial statements of an organization, but the policies, procedures and compliance to statutory regulations.

COVID-19 is a coronavirus disease 2019, and is referred to as a sickness caused by a novel coronavirus which caused severe acute respiratory problem identified amid an outbreak of respiratory illness case in Wuhan city in China. It was officially reported to World Health Organization (WHO) on 31ST December 2019. The outbreak of COVID-19 was declared as a global pandemic by WHO in 30th January 2020, and on 11th March 2020 it was declared as a global pandemic (Cennimo, 2020; Kaka, 2020). Thus, the following sections concentrates on discussing how COVID-19 has affected auditing and audit reports.

\section{Method}

For the purpose of this research, the central objective of this paper is to highlights some of the practical challenges auditors may face in auditing financial statements in the light of COVID-19 and areas to put more emphasis in their audit reports. The researchers used the documentary research design in this study. Secondary data were collected or obtained from the journal, books, internet sources, and newspapers, magazines, newsletters that are needed for this research.

\section{Discussion}

Items in the financial statements affected by covid-19 pandemic

The items in the financial statements that are affected by lockdown due to covid-19 as stated by Crowe (2020) are:

1. Receivables: debt collection will now take longer time due to lockdown imposed as a result of covid-19. The consequence is that some of the debt in the financial statements may become bad, and the organization does not have any alternative than to consider the debt as bad debt.
Thus, auditors are expected to check and assess the amount of bad debts and give allowance for credit losses where possible.

2. Inventories: the lockdown imposes restriction on movement which in turn affects businesses, as some were not able to sell their products, and some goods perished, while some others become obsolesce and outdated. Thus, this affected the financial statements as slow moving stocks must have to be written down or reported as scrape. Therefore, issues auditors should look for during an audit is to assess the amount of slow moving stocks.

3. Loans: COVID-19 has made persons and corporate bodies to breach loan agreements, due to their inability to honor maturing obligation of loan repayments. Thus, auditors are expected to reclassify defaulted loans to current liabilities and assess as to whether the corporate entity has a going concern issue.

4. Bank and cash: regular cash flows in and out of the organizations are affected and cash depletion set in to persons, trade, businesses and corporate organizations. This also affect the going concern issues of persons, businesses and organizations. Thus, in situation like this, auditors are to give more emphasis on the assessment of the ability of the organizations or persons to survived and continue as a going concern.

5. Capital: capital of some businesses have been eroded due to the pandemic covid-19. This has affected the existence and continue operation (going concern) issues in the financial statements. Hence, it is expected that the ability of the organization to keep existing as a going concern most be assessed by auditors.

6. Revenue: because the COVID-19 pandemic broad about restrictions in movement and closure of businesses, some corporate organizations witness and experience a major drop in revenue generation. This has affected the sustainability of some businesses. Issues that must be tackle and addressed is to assess the capacity and capability of the organization to continue their operation as a going concern.

7. Other income statements items: majority of organizations witness a significant fall in business volume which gave birth to excess capacity. The excess capacity has affect the financial statements, with provision for onerous contracts, write-off of excess overhead cost. Issues auditors should look for includes the 
assessment of adequacy of provisions and writeoffs.

8. Investments: there was also a drop in market value of a lot of organizations, which has impaired the stock prices in the market. Auditors should check the written down value to market value of stocks held by organizations.

9. Subsequent events: subsequent events led to drastic change in business environment, the financial statements and disclosures. Auditors should assess whether subsequent events should be an adjusted or non-adjusted event.

\section{Audit issues and the procedures}

Audit issues and the procedures to assess the effect of covid-19 pandemic on financial statements according to ACCA (2020) and Crowe (2020) are as follows:

1. Revenue contracts: unprecedented or unexpected changes in the business environment have gave birth to variation in some contract agreements entered into by organization. This changes are made up of penalties or refunds for failure to fulfilled contract agreements, contract modifications and changes in enforceability of contracts. Therefore, the effect of these changes need to be investigated, disclosed or quantified.

2. Inventories: this has to do with identifying changes in the net realizable values either due to obsolesce (out dated) or reduction in value of the selling price.

3. Impairment of non-financial assets: such as buildings and equipment. Auditor should identify and discover indications of impairment, changes in key drivers and assumptions used in estimating the receivables accounts of the productive assets.

4. Going concern: material uncertainties may also put a significant doubt on the ability of corporate organizations to keep existing as a going concern.

5. Receivables: greater judgement is needed from the auditor in assessing the expected credit loss due to the lockdown as a result of the pandemic.

6. Fixed production overheads: a higher amount of unallocated fixed overheads has to be expensed off due to abnormal production capacity/low production volume.

7. Lease contracts: to identify and account for any lease rent concessions.
8. Fair value of unquoted equity instruments: to update key drivers and assumptions used in estimating the recoverable amounts of the productive assets.

9. Provision for onerous contracts: a provision is needed when unavoidable cost of meeting the obligations exceed the benefits expected to be gotten under the contracts.

10. Government support: to determine the right or correct accounting treatment of government support such as economic stimulus package. Is a government grant that should be accounted for under SAS the accounting for government grants as disclosure of government assistance?

11. Impact on auditors' report: to evaluate whether the effect of COVID-19 is a key audit issue or matter. Depending on the resolution of accounting and auditing matters due to COVID19, possibilities exists as to whether it is necessary for the issuance of modified opinion or inclusion of a separate section under material uncertainty related to un going concern in the audit report.

12. Breach of loan covenants: the auditor should determine how a breach of loan agreement may affect the timing of repayment of the defaulted loan (such as the loan on demand) and how it affects the classification of the related liabilities at the reporting date. This also affect the assessment of the organizations ability to continue to operate as a going concern.

13. Disclosures in financial statements: more comprehensiveness is required of significant accounting judgements, estimates and assumptions used in preparing the financial statements that could result in material adjustments to the carrying amount of assets and liabilities.

14. Foreign exchange transactions: to consider the impacts of significant fluctuations in foreign exchange rates on the operations of the organization and the effectiveness of hedge accounting.

15. Events after the reporting date: to carefully evaluate whether information on covid-19 that are made available after the reporting date is an adjusting or non-adjusting event for accounting purposes. Financial statements have to be updated if the event is a significant adjusting event, otherwise, a disclosure is needed. 


\section{Audit considerations (possible audit scope and limitations)}

In the mixed of pandemic like COVID-19, performing audit procedures is troublesome for many auditors. In some instances, auditors may come across limitation in scope. The limitations in scope to possibly address by auditors as opined by ACC (2020); Arnold (2020) and Illuzi et al. (2020), includes the following:

1. Understanding and testing internal control: one of the professional responsibility of auditors is to plan and carry out any audit or assurance assignment with professional skepticism. Professional skepticism according to Illuzi et al. (2020) is an attitude and behavior that involves being alert, a questioning mind to situations that may show possible misstatement due errors or fraud, and a critical assessment of audit evidence. It is expected that auditors must always be on guide, especially, during pandemic like COVID-19 where many auditors are working remotely. The quality of audit evidence gathered and whether the audit evidence is enough and sufficient to decrease audit risk to a reasonable level. Thus, the gathering of the evidence needs professional judgement about what the evidence contains and indicates. There have been delay in the issuance of financial statements due to COVID-19, which led to unprepared closures and uncertainties in demand, and a low priority in completion of procedures required to give historical financial statements. If possible, the managements and auditors should consider delaying the issuance of financial statements until the situation is enhanced. In the meantime, management of corporates organizations may choose to pass the information to the financial statements users via drafts or projections. Although, this process should have to be carefully look into before such projections can be made. In an instance where there is delay in the preparation and presentation of the financial statements, auditors are required to look at the need to extend subsequent events and auditing procedures as necessary as possible. Therefore, the possible audit scope and limitations as stated by ACCA (2020) are in the aspect of:

2. Performing physical stock observation: auditors are expected to gather enough, relevant and related audit evidence concerning the condition and existence of stocks, if stocks are material to the financial statements of the organization. The auditor can do this via physical stock count. But for organization with financial year ends coincide with covid-19 pandemic, where auditors were unable to travelled due to travel restriction, may face challenges in carrying out physical observations of stock. Thus, in an event where the clients were unable to undertake physical stock counts at the end of the year, an alternative counts date and stock transaction can be fixed or scheduled. However, if the auditor was unable to attend stock counts due to travel restriction, the auditor should take advantage of technology, by the use of camera and live video or virtual means to observe the stock counts. Where client was unable to undertake physical stock counts at the end of the year, or rather auditors where unable to gather enough audit evidence as to whether the counting was performed properly, (due to their inability to attend physical stock count remotely or in person, or they were un able to test roll forward of stock from balance sheet date to the observation of inventory date), these problems may present scope limitations that will affect auditors' reports. In an instance, where stock balances are material but are not pervasive, this can lead to qualified audit opinions. Some auditors might have clients discuss with financial statements users as to whether the review engagements for the year end should be complemented with agreed upon procedures on the stock after year end when counts of stock will be carried out.

3. Access to clients' records: in an instance where there is crisis, just like the pandemic COVID-19, and there was restriction in movement, getting access to clients' books and records may be difficult to some auditors, most especially for those clients that keeps records on papers. However, auditors can obtain copies or scans copies of key records, but he has to be sure that the records are accurate, authentic and complete. If auditors are unable to have access to the books and records, the auditors are to inform the clients that audit cannot be completed, until all records and books are accessed.

4. Understanding and testing internal control: the pandemic related problems that may arise when clients' sites are closed and auditors are not able to carry out audit on sites, are; auditors did not have enough access to client system of internal control, and they did not access that system 
remotely. For example, how does the auditor assess some controls activities, the monitoring components and control environment remotely? If management had to change some aspect of the internal control process due to staff working from homes, auditors should discuss any new procedure and agreed on those new controls that have been put in place and make sure they are operating effectively. In addition to that, auditors are required to inquire as to whether there are some changes in the client system of internal control at the time of carrying the preliminary work. If there are changes to accommodate remote work forces and process flows, auditors must determine how much they can rely on those controls that are introduced newly for the portion of the remaining year.

5. Account confirmation: external confirmations received from third parties by an auditor may be more reliable than the evidence gotten internally by an organization. Especially in an instance where the client site or offices are locked and key staff no longer goes to the office. Thus, getting external confirmation can be used as another alternative way of getting audit evidence. However, in a situation where audit confirmations are not received by auditors, possibly as a result of mail closure issues, auditors would have to design an additional process to get enough and required audit evidence in connection to account receivables. After the design and test carry out on those balances, the inability to or none receipt of confirmations would not lead to scope limitations. Alternatively, if auditor did not obtain enough evidence and is depending heavily on receipt of audit confirmations as the main source of audit evidence, the none receipt could lead to scope limitations (most especially, if the balances are material to the financial statements). Lastly, auditors are required to look at the possibility of sending electronic confirmations instead of paper, due to increasing shutdown and movement of business to online and virtual technology.

6. Audit plan: auditors are required to plan their work and adequately supervise their workers as a matter of standards. Auditors must know that working remotely is not an excuse for his inability to plan audit meetings. They should make sure they are having discussions on engagement risk when the need arises with the engagement team before commencing the audit work.

7. The nature and extent of planning activities that are necessary depend on the size and complexity of the company, the auditor's previous experience with the company, and changes in circumstances that occur during the audit. When developing the audit strategy and audit plan, the auditor should evaluate whether the following matters are important to the company's financial statements and internal control over financial reporting and, if so, how they will affect the auditor's procedures:

a. Knowledge of the company's internal control over financial reporting obtained during other engagements performed by the auditor;

b. Matters affecting the industry in which the company operates, such as financial reporting practices, economic conditions, laws and regulations, and technological changes;

c. Matters relating to the company's business, including its organization, operating characteristics, and capital structure;

d. The extent of recent changes, if any, in the company, its operations, or its internal control over financial reporting;

e. The auditor's preliminary judgments about materiality, risk, and, in integrated audits, other factors relating to the determination of material weaknesses;

f. Control deficiencies previously communicated to the audit committee or management;

g. Legal or regulatory matters of which the company is aware;

h. The type and extent of available evidence related to the effectiveness of the company's internal control over financial reporting;

i. Preliminary judgments about the effectiveness of internal control over financial reporting;

j. Public information about the company relevant to the evaluation of the likelihood of material financial statement misstatements and the effectiveness of the company's internal control over financial reporting;

k. Knowledge about risks related to the company evaluated as part of the auditor's client acceptance and retention evaluation.

8. Fraud in the financial statements: despite the fact that there are lay down procedures and requirements, current happening of COVID-19 
pandemic allows inquiries to be carried out virtually or via video conferencing. This will allow the auditor to see the body language of the person being investigated. Similarly, auditors are expected to have discussion with the management concerning management assessment risk of fraud and management process for identifying, monitoring and responding to risk of fraud. For any reason, auditors are not able to fulfill this process, they will consider it as scope limitations.

9. Forecasting related to going concern assumption: the continuing existence of an organization as a going concern is mostly affected by one factor or another like; the industry, geographical area, where the organization operates, the availability and accessibility of finance for the organization, financial health of suppliers and customers of an organization. The consequences of COVID-19 may affect the above factors and may lead to the deterioration in the organizations operating results and their financial position. Thus, auditors and organization may be required to look at current important and relevant information in connection with the assessments of going concern. As the situation are changing every now and then as a result of COVID-19 and is having severe effects on many organizations such as airlines, restaurants, entertainments. The ability of the management to evaluate events and situations that may affect the organization to continue its operation as a going concern, will be found under the Generally Accepted Accounting Principles (GAAP), and Financial Accounting Standard Board (FASB) accounting standard codification 205-240 as concern presentation of financial statements. Auditors are expected to gain access to the management evaluation of the organization as to whether it will continue as a going concern, or believe and accept that the supporting documents are accurate and complete. Where it is not, auditors are required to consider it as scope limitations. Although in practice, auditors should be reminded that management evaluation, or assumption or forecast might be hard to carry out in the present situation of lockdown. Therefore, management best estimates are to be accepted and will not lead to scope limitations.

10. Performing subsequent events: for audits of calendar year end 2019 financial statements, COVID-19 subsequent events are possibly, and is going to be type 11 events. Type 11 events are events that should give proofs of conditions that arose after the date of the financial statements. Thus, COVID-19 pandemic related subsequent events that needs an adjustment to the financial statements or additional disclosures must be considered. Auditors must have to work closely with clients to make sure subsequent events are discovered correctly and it is shown in the financial statements as instructed in FASB 855 , called subsequent events. For instance, it might be fall in the fair value of investments. Thus, disclosure of this event may be required even though, it would not be recognized in the financial statements. Auditors should examine or investigate the appropriateness of subsequent event disclosures in the financial statements, if it is not disclosed, a modified auditor's opinion may be required. For audits of clients with year ends that fall within 2020 called type 1 events, pandemic related events may need adjustments to the financial statements or conditions that arose at the date of the financial statements.

11. Obtaining management representations: additional representation letter must have to be issued in pandemic situation, apart from the management representation letter issued earlier on. This will also depend on the circumstances of the audit engagement. The additional representation letter may be concern about subsequent events, fraud, going concern assumption, risk and uncertainty and significant estimates. Thus, during pandemic that resulted to lockdown and the inability to access offices physically to sign documents, management representation letter can be obtain electronically. Similarly, management representation can be obtained on plain paper or on company's letter headed paper. If it is in plain paper, the only thing that is needed is the name of the organization and address to appear in it at the top of the letter, as the standard did not emphasize the use of letter headed paper as the only option. However, failure to get all the representations in the management letter does not lead to scope limitation, because it may sometime mistakenly be omitted from management representation letter. Auditors are expected to discuss with the managements, if any information is omitted from the requested written representations.

12. Audit evidence: IAS 330 sub section 12 (a \& b) states that if an auditor obtains audit evidence about the operating effectiveness of controls during an interim period, the auditor shall obtain 
audit evidence about significant changes to those controls, subsequent to the interim period; and determine the additional audit evidence to be obtained for the remaining period. Judgement will be needed to assess the quality and authenticity of the evidence for the reason it was collected. Professional skepticism must have to be exercised by auditors concerning the evidence gathered via electronic means or source. Auditors are expected to design other audit procedures to test the reliability of the evidence obtained electronically, in an instance where original physical source documents cannot be gotten, then the auditor should check the controls of the process from which electronic evidence was produced (Arnold, 2020).

13. Fraud risk: in this time of uncertainties, auditor are expected to be on high alert for fraud risk that may take place. This is possible with the organizations where workforce is moving out of the typical environment and some key personnel have been laid off. This scenario, could lead to a breakdown of the internal control system. Therefore, auditors should adjust audit procedures as a matter of necessity to help in reducing any potential fraud risks that could have a material impact on the financial statements.

\section{Audit report scenarios}

Some of the audit scenarios to be discovered in audit reports during the pandemic COVID-19, that readers of audit reports are expected to give more emphasis and attention are:

1. Inability to attend stock takes: this is an area of most concern to auditors because majority of the organizations were not able to carry out year-end stock counts as at March 31, 2020. However, if the organization was able to undertake the stock counts and auditors under lockdowns where not able to attend. Thus, auditing standards requires auditors to be present during stock counts unless it is not possible to attend due to circumstances beyond his control. Failure or inability of the auditors to attend, may lead him to states that there is "limitation of scope" in the audit reports signifying that the auditor opinion is qualified. Any qualified report, gives a danger signed on the organization, although, it is an unavoidable outcome due to lockdown in March 31, 2020 that led to such qualification and hence, it can be said to be a technical qualification. There may be a lot of reports with qualification for inability to attend stock takes.

2. Multiple uncertainties: in an instance, where there are many uncertainty surrounding an organization or lack of enough justifiable audit evidence to be provide to the auditors, may lead to disclaimer opinion. This shows that the auditor is unable to form an opinion on the financial statements because the issues are pervasive and material. This is a serious danger signal (red traffic light).

3. Going concern: is an audit report scenario that is an area with moderate concern. Covenant issues may come up in certain areas, most especially at this period that cash flows and results are being increasingly put under pressure. Organizations are earlier on encouraged to always engaged in bank financing, so that consideration of breaches in factual or potential agreements can be easily traced. For instance, if an organization has broken financial agreements before or after March 31, 2020 and has not finished negotiation with the bank to reset agreements before signing the financial statements, this may have an advance effect on the audit report. Auditors are expected to check the overall financial position of an organization and look at the natures of agreements, breaches of the covenants, close calls and headroom available and forecast compliance and many more. The auditors' reports should include in a paragraph, a "material uncertainty with respect to going concern" if he found out that there are some elements of breaches in the agreement. This statement is not a qualification, but to serve as a warning signal to users of financial statements.

4. Key audit matters: these are areas of least concern. It is expected that there is going to be a rise in the figures of Key Audit Matters (KAM) in audit reports, due to increase in uncertainty and the judgements in the financial statements. A section is expected to be created in the audit reports of all organization that has a great level of public accountability. Key audit matters gives transparency concerning issues in the judgement of the auditors, which is very importance in the audit with the management. However, KAM are to be expected and are normal in an organization, which is a green traffic light. Thus, the material uncertainty in the valuation reports observed, may be shown in KAM audit reports. To identify and see key risk areas in the financial statement by banks and other users of audit reports. KAM 
will give information pertaining to the key issues that the auditor has emphasize on.

\section{Modification to the opinion in the independent auditors' reports}

In forming an opinion on the financial statement, the auditor shall state in his opinion that in all material respect that the financial statement is prepared in accordance with applicable financial frameworks; and shall conclude as to whether he obtains all the necessary audit evidence about whether the financial statement as a whole are free from all material misstatements whether due to fraud or errors (IAS $700(10 \& 11)$. The challenges auditors are presently encountering in getting enough and the right audit evidence due to uncertainty caused by pandemic coronavirus, could lead to the modifications of their opinion on the financial statements. International Standard Auditing (ISA) 705 (revised) has modify the opinion on the independent auditors' reports (ACCA, 2020). The modify opinion are:

1. A qualified opinion: ISA 705 (Revised) opined that auditor should give a qualified opinion when:

a. After the auditor might have obtained enough and the right audit evidence, it is expected that he should conclude that misstatements whether personally or collectively are considered to be material, but not pervasive to the financial statements; or

b. Alternatively, when the auditor is not able to get enough appropriate audit evidence that can assist him base his opinion, he should conclude that the possible effects on the financial statements of undetected misstatements, if any, could be material and not pervasive.

2. Advance audit opinion: ISA 570(8) (Revised), states that an adverse opinion should be stated by the auditor, if having gotten enough and the right audit evidence, should concludes that misstatements, personally or in group, are both material and pervasive to the financial statements. While, IAS 706(8) (Revised) if the auditors consider it necessary to draw the attention of the users to the matter presented or disclosure in the financial statement that, in the auditor's judgment it is of such importance that it is fundament to users understanding of the financial statements the auditor should include an emphasis that, he is not required to modify in accordance to IAS 705 in his reports as a result of the matter.

3. Disclaimer of opinion: ISA 570(9) states that auditors should disclaim an opinion, when they are unable to get enough and the right audit evidence on which to base their opinion, and concludes that the possible effects on the financial statements of unidentified misstatements, if there is any, should be both considered as material and pervasive. For instance, if an auditor is unable to get enough and appropriate audit evidence concerning the physical existence and the situation of stocks, as a result of restriction due to COVID-19 pandemic, then depending on the materiality and pervasiveness of this to the financial statements as a whole, auditor may be required to make a decision as to which modification in their or his opinion is going to be more appropriate.

\section{Conclusion}

The objective of this paper is to highlights some of the practical challenges auditors may face in auditing financial statements in the light of COVID-19 and areas to put more emphasis in their audit reports. The paper deals with auditing, COVID-19, items in the financial statements affected by COVID-19, audit issues and procedures, audit considerations, audit reports scenarios and modification to the opinion in audit reports. The paper discovered that COVID-19 is having an unprecedented impact on financial statements and auditors' reports, and highlighted some of the key areas an auditor, management and users of audit reports are to be conscious of when auditing and reading the audit reports. The paper also found out that Professional associations, accounting and auditing bodies are monitoring issues and situations as they unfold that may affect the financial statements and audits reports due to the impact of COVID- 19 . Moreover, they are ready all the time to issue out additional guidelines as new development unfold, and continue to update professional accountants on issues patterning to the continuity of the organization business, workforce, economic impact and other resources to help their members to serve their clients better in this period of pandemic. The study recommends that, Auditors are expected to display enough professional skepticism and judgement and be focused on public interest and ethical responsibilities bestowed on them, and continue to apply the 
principles contain in auditing standards fully, as well as comply with the fundamental principles of professional competence, confidentiality, objectivity, independence, care and skills and behave professionally. These are keys that will preserve and expand auditors trust in the face of the public. Secondly, technology is a most have if auditors want to survived and continue in business in this period of COVID-19 and in the future. Lastly, an empirical study should be carried out to practically assess the performance of business organizations audit reports during and after the pandemic in order to appraise the performance of auditors on the ability to gather enough and relevant evidence to be used in forming their opinion.

\section{Reference}

ACCA, 2020. The impact of covid-19 on audit and assurance: challenges and considerations, Retrieved from htpps://www.accaglobal.com/gb/en/professional-insights-globaleconomics/covid-19-a-global-survey.html. Accessed August 1, 2020 .

Arnold, C., 2020. Summary of COVID-19 audit considerations. International Federation of Accountants, Retrieved from https://www.fac.org/knowledge-gateway/support-internationalstandard/discussion/summary-covid-19-audit-consideration. Accessed July 20, 2020

Cennimo, D.J., 2020. What is COVID-19. News and Perspectives, 25 Medscape, Retrieved from https://www.medscape.com/answers/2500114-19740114questions-answers. Accessed August 9, 2020.
Crowe, 2020. Accounting and auditing implications of covid-19. Audit/Tax/Advisory, Retrieved from https://www. Crowe.my. Accessed August 1, 2020.

Dohner, B. \& Mayes, C., 2020. Auditing during covid-19, 6 areas to focus on. Journal of Accounting, a publication of American Institute of CPAs, 14-18.

Gould, S. \& Arnold, C., 2020. The financial reporting implications of covid-19, issues and insights. Supporting International Standard, April, Retrieved from https://www.ifac.org/knowledgegateway/supporting-international-standard/discussion/financial. Reporting. Accessed August, 6, 2020.

Illuzzi, K., Landes, C., Durak, R., \& Groskopt, T., 2020. Consequences of covid-19 potential auditing challenges. Center for Plain English Accounting. AICPA'S National A\&A Resource Center, Special Report.

Kaka, E.J., 2020. The COVID-19 crisis, risk compliance and its aftermath on professional accountants. Indonesian Journal of Accounting and Governance, 4(1), pp65-81.

Shires, K., 2020. Likely impact of covid-19 on audit reports. Price Waterhouse Coopers and PWClegal New, NewZeland. Retrieved from https://www.pwc.co.nz/publication/2020/pwc-covid-19likely-impact-on-audit-reports.pdf. Accessed July 13, 2020.

Suffield, M., 2020. Covid-19 having significant impact on the world auditors. Professional insight, ACCA. Retrieved from https://www.accaglobal.com. Accessed August 2, 2020.

Poole, V., 2020. Accounting consideration related to coronavirus disease 2019. IFRS in Focus, March, Retrieved from https://www.ifrs.com. Accessed July 15, 2020.

Thompson, H., 2020. Covid-19 having significant impact on the world auditors. The Global Body of Professional Accountants, Surrey Business School, University of Surrey, Retrieved from https://www.accaglobal.com 